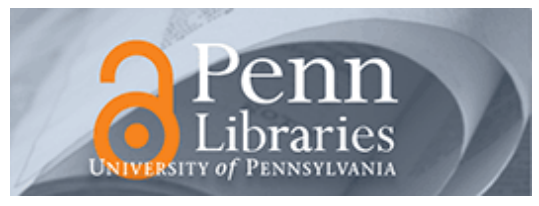

University of Pennsylvania ScholarlyCommons

$7-2015$

\title{
Brain Imaging Research on Psychopathy: Implications for Punishment, Prediction, and Treatment in Youth and Adults
}

\author{
Rebecca Umbach \\ University of Pennsylvania, rumbach@sas.upenn.edu \\ Colleen Berryessa \\ University of Pennsylvania, berrco@sas.upenn.edu \\ Adrian Raine \\ University of Pennsylvania, araine@sas.upenn.edu
}

Follow this and additional works at: https://repository.upenn.edu/neuroethics_pubs

Part of the Bioethics and Medical Ethics Commons, Neuroscience and Neurobiology Commons, and the Neurosciences Commons

\section{Recommended Citation}

Umbach, R., Berryessa, C., \& Raine, A. (2015). Brain Imaging Research on Psychopathy: Implications for Punishment, Prediction, and Treatment in Youth and Adults. Journal of Criminal Justice, 43 (4), 295-306. http://dx.doi.org/10.1016/j.jcrimjus.2015.04.003 


\title{
Brain Imaging Research on Psychopathy: Implications for Punishment, Prediction, and Treatment in Youth and Adults
}

\begin{abstract}
While there has been an exponential increase in brain imaging research on psychopathy in the past two decades, knowledge on the brain basis to child and adolescent psychopathic-like behavior is relatively new. This adult and child research has potential future implications for the development of new interventions, prediction of future offending, and punishment. This review examines both adult and child literatures on the neural basis of psychopathy, together with implications for the criminal justice system. The adult imaging literature provides growing evidence for amygdala structural and functional impairments in psychopaths, and more variable evidence for prefrontal deficits. The emerging child and adolescent imaging literature with notable exceptions broadly parallels these adult findings and may help explain the development of fearlessness, disinhibition, and lack of empathy. This knowledge places policy makers at a crossroads. Should new biological interventions be developed to remediate these brain abnormalities? Would imaging be used in the future to predict offending? Could imaging findings help excuse psychopathic behavior or alternatively argue for longer sentences for public protection? This review attempts to address these issues at the child and adult levels and provides directions for future research that include the incorporation of biological measures into treatment programs.
\end{abstract}

\section{Keywords}

MRI, amygdala, psychopathy, prefrontal, adolescent, treatment

\section{Disciplines}

Bioethics and Medical Ethics | Neuroscience and Neurobiology | Neurosciences 
This is a preprint of an article accepted for publication in the Journal of Criminal Justice.

Umbach, R., Berryessa, C. M., \& Raine, A. (2015). Brain imaging research on psychopathy: Implications for punishment, prediction, and treatment in youth and adults. Journal of Criminal Justice. doi:10.1016/j.jcrimjus.2015.04.003

Copyright (C) 2015 (Elsevier) 


\title{
Brain Imaging Research on Psychopathy: Implications for Punishment, Prediction, and Treatment in Youth and Adults
}

\section{Rebecca Umbach*, Colleen Berryessa*, and Adrian Raine}

\author{
Department of Criminology, \\ University of Pennsylvania \\ * Equal contributions to the manuscript.
}

Key words: MRI, amygdala, psychopathy, prefrontal, adolescent, treatment

Total words: 9,740

Correspondence to:

Rebecca Umbach

Department of Criminology

University of Pennsylvania,

Philadelphia, PA 19103

Email: rumbach@sas.upenn.edu

Colleen Berryessa

Department of Criminology

University of Pennsylvania

Philadelphia, PA 19103

Email: berrco@sas.upenn.edu 


\begin{abstract}
While there has been an exponential increase in brain imaging research on psychopathy in the past two decades, knowledge on the brain basis to child and adolescent psychopathic-like behavior is relatively new. This adult and child research has potential future implications for the development of new interventions, prediction of future offending, and punishment. This review examines both adult and child literatures on the neural basis of psychopathy, together with implications for the criminal justice system. The adult imaging literature provides growing evidence for amygdala structural and functional impairments in psychopaths, and more variable evidence for prefrontal deficits. The emerging child and adolescent imaging literature with notable exceptions broadly parallels these adult findings and may help explain the development of fearlessness, disinhibition, and lack of empathy. This knowledge places policy makers at a crossroads. Should new biological interventions be developed to remediate these brain abnormalities? Would imaging be used in the future to predict offending? Could imaging findings help excuse psychopathic behavior or alternatively argue for longer sentences for public protection? This review attempts to address these issues at the child and adult levels and provides directions for future research that include the incorporation of biological measures into treatment programs.
\end{abstract}




\section{Introduction}

Psychopathy is a serious personality disorder that is disproportionately costly to society. Psychopaths are significantly more likely to make contact with the criminal justice system (Kiehl \& Hoffman, 2010), commit violent crime (Carre, Hyde, Neumann, Viding, \& Hariri, 2013), act out while incarcerated (Guy, Edens, Anthony, \& Douglas, 2005), manage early release (Porter, Brinke, \& Wilson, 2009), and recidivate (e.g. Hart, Kropp, \& Hare, 1988; Porter, Birt, \& Boer, 2001; Kiehl \& Hoffman, 2010; Richards, Casey, \& Lucente, 2003; Cornell et al., 1996; Harris, Rice, \& Cormier, 1991). Psychopathy is argued not to be culture specific—psychopaths are claimed to be found in countries all around the world (De Oliveira-Souza, Moll, Ignacio, \& Hare, 2008; Serin, Peters \& Barbaree, 1990; Sevecke, Lehmkuhl, \& Krischer, 2009) although whether the construct applies in East Asian countries remains to be firmly established. As such, psychopaths warrant worldwide scrutiny by researchers, and attention by lawmakers.

Related in symptomatology to antisocial personality disorder and narcissistic personality disorder, it is not included in the Diagnostic and Statistical Manual of Mental Disorders (DSM). Regardless of this exclusion, psychopathy is widely acknowledged in the clinical, academic, and criminal justice worlds as a significant personality disorder. Importantly, psychopaths demonstrate signature deficiencies in affective experience, including lack of empathy, lack of guilt or remorse, and impaired affective processing. With the advancement of imaging technology and neural pathway understanding, evidence supporting theories of neurological substrates of adult psychopathy, particularly their affective deficits, is mounting. While brain imaging research has been increasingly conducted on adult psychopaths, it is only quite recently that this technology has been applied to juveniles with disruptive behavior disorders (DBD) such as conduct disorder and callous unemotional traits (CU) (De Brito et al., 2009). 
This selective review will focus specifically on studies that used brain imaging (whether functional MRI or structural MRI) to measure structural or functional differences in psychopathic adults, or children with DBD and CU traits. Furthermore, it will selectively address only two main areas of the brain - the prefrontal cortex and the amygdala - which have been most extensively researched and have been consistently implicated in psychopathy. In the first part of this paper, for each of these brain areas we first review structural imaging research followed by functional imaging. After reviewing the adult literature, we then turn to imaging research on these same brain regions in children with psychopathic-like traits. In the second part of the paper we turn to implications of this basic science research for the criminal justice system. Specifically we cover three main areas: punishment, prediction, and intervention. Finally, we turn to broader implications for juveniles with psychopathic-like traits in the criminal justice system, together with guidelines for future research.

\section{Amygdala Abnormalities in Adult Psychopaths}

The amygdala has been identified as an area of interest in many brain imaging studies assessing neurological correlates of psychopathy. It is an important paralimbic structure that is considered the center of emotion processing, including empathy and conditioned fear acquisition and extinction (LaBar, Gatenby, Gore, LeDoux, \& Phelps, 1998). Lesions to the amygdala impair visual recognition of emotion (Adolphs, Tranel, Damasio, \& Damasio, 1994), auditory recognition of fear and anger (Scott et al., 1997), and in animals, has been shown to disrupt inhibitory avoidance learning (Bermudez-Rattoni \& McGaugh, 1991) and conditioned fear (Hitchcock \& Davis, 1986). In psychopaths, symptoms such as lack of empathy, blunted affect, and lack of fear are directly related to impaired emotion processing, and by implication the amygdala. Studies have hypothesized that impaired fear recognition plays a role in the lack of 
empathy considered a core characteristic of psychopathy (Blair, 2008). As such, while the functional neuroanatomy of psychopathy involves multiple brain areas, a focus on the amygdala bears directly on the core feature of psychopathy and for this reason has garnered considerable attention in both psychopathic adults and adolescents.

\section{$\underline{\text { Structural MRI }}$}

In adults, findings have not been completely consistent, but generally trend towards a volume reduction in the amygdala associated with psychopathy (Yang, Raine, Narr, Colletti, \& Toga, 2009; Boccardi et al. 2011; Ermer, Cope, Nyalakanti, Calhoun, \& Kiehl, 2012; Tiihonen et al., 2000; see Schiltz et al. 2007 for a null finding). In addition to their finding of significant bilateral volume reductions in psychopaths, Yang et al. (2009) identified localized surface deformations in four of the 13 nuclei: the basolateral, lateral, cortical, and central nuclei. Yang, Raine, Colletti, Toga, and Narr (2010) further found that only unsuccessful (caught) psychopaths demonstrated significant amygdala structural deficits (basolateral and superficial nuclei), while successful (uncaught) psychopaths resembled controls. They argued that the structural deformations in these specific nuclei within the amygdala may contribute to the unsuccessful psychopaths' inability to learn from punishment, response perseveration, and reduced stress and anxiety which can contribute to poor socialization.

\section{Functional MRI}

Findings from fMRI research generally dovetail with structural imaging findings in observing reduced amygdala activation in psychopaths. The amygdala of psychopaths have has been found to be hypoactive during fear conditioning (Birbaumer et al., 2005), moral decisionmaking (Glenn, Raine, \& Schug, 2009), and social cooperation (Rilling et al., 2007). As expected, studies have also found the amygdala to be hypoactive in response to fearful faces or 
other affect-related activity (e.g. Carre, et al., 2013, Kiehl et al., 2001). Nevertheless, Muller et al. (2003) found that psychopaths had increased activation in the amygdala (in addition to increased prefrontal activation) when viewing negative content (e.g. pictures of threatening animals, wounded people) which they interpreted as reflecting abnormal prefrontal - amygdala communication. In interpreting this apparent conflicting amygdala finding, Kiehl et al. (2006) comment that the methodology used in Muller et al. (2003) differed from most other studies in that it involved a passive viewing paradigm which did not necessarily require full participation, nor the evaluation of affect.

\section{Frontal Abnormalities in Adult Psychopaths}

The prefrontal cortex (PFC) is a major area implicated in antisocial and/or psychopathic individuals (see Blair, 2007). Responsible for a wide range of functions, it is perhaps best known as the center of "executive functioning", functions which include behavioral flexibility, learning, sustained attention, and working memory (Puig \& Gulledge, 2011). It is also part of a wider neural circuit underlying moral decision making and reward/punishment processing (e.g. Ciaramelli, Muccioli, Ladavas, \& di Pellegrino, 2007; Glenn, Raine, \& Schug, 2009). A variety of studies have tackled the question of whether prefrontal structure and function are related to psychopathy and to antisocial behavior in general. Additionally, some studies (e.g. Yang et al. 2005; Raine et al. 1998) have worked to tease apart the complexities differentiating types of offenders and related prefrontal brain differences.

\section{$\underline{\text { Structural MRI }}$}

A meta-analysis of $12 \mathrm{sMRI}$ studies examined the relationship between the prefrontal cortex and various forms of antisocial behavior (violence, psychopathy, and generic antisociality (Yang \& Raine 2009). They found a significant association between ASB and reduced structure 
in the prefrontal cortex $(\mathrm{d}=-0.37)$, although the small number of structural studies $(\mathrm{n}=12)$ did not allow for analysis of specific regions within the prefrontal cortex. The effect size (Cohen's d) for psychopathy (including both functional and structural studies) was -0.56 , indicating a good fit for an association between psychopathy and prefrontal abnormalities, although their sample of studies for psychopathy was small $(\mathrm{N}=9)$.

Since Yang and Raine's (2009) meta-analysis, more studies have focused specifically on the relationship between the reduction in the prefrontal cortex and psychopathy. Gregory et al. (2012) found that individuals with psychopathy, compared to antisocial personality disorder and controls, demonstrated significantly reduced grey matter volumes bilaterally in the anterior rostral prefrontal cortex. Similarly, at least three studies found that psychopathy was associated with decreased grey matter (Ermer et al., 2012, De Oliverira-Souza et al., 2008) and area measurements (Dolan, Deakin, Roberts, \& Anderson, 2002) in a variety of brain areas, including the orbitofrontal cortex. Bertsch et al. (2013) observed volumetric reductions in the dorsomedial prefrontal cortex in addition to the posterior cingulate/precuneus. Dolan et al. (2002) also found smaller dorsomedial prefrontal cortex area measurements. Howner et al. (2012) found that psychopaths had thinner cortex in the entire right hemisphere, bilaterally in the temporal lobes, and trended towards thinner cortex bilaterally in the frontal lobes, although the p values only approaching significance (left: $\mathrm{p}=0.072$ right: $\mathrm{p}=0.064$ ). Craig et al. (2009) examined the integrity of the uncinate fasciculus (UF) in psychopaths, which links the amygdala and the OFC and found significantly reduced integrity compared to controls. They also found a negative correlation between UF integrity and antisocial behavior. This finding indicates that even beyond mere functional or structural differences in the amygdala and orbitofrontal cortex, the connections between implicated brain areas may very well also be dysfunctional. 
While findings are generally consistent in finding structural frontal impairments in psychopaths, null findings have been reported. At least one study (Dolan et al., 2002) found no significant differences in frontal volumes between a psychopathic group and controls, noting that the psychopathic subjects had significantly larger dorsolateral prefrontal volumes. Given the general trend towards volumetric reduction, heterogeneity in findings need to be recognized and moderators examined in future meta-analyses.

\section{Functional MRI}

Dovetailing with the structural MRI studies, fMRI studies have generally demonstrated reduced prefrontal cortex functioning in psychopaths. In a review based on 15 functional neuroimaging studies, Pridmore, Chambers and MacArthur (2005) conclude that there is evidence for dysfunction in specific frontal and temporal lobe areas in psychopathy. Yang and Raine (2009) reported a medium effect size $(d=-.056)$ in 9 functional and structural studies of psychopaths that was statistically non-significant $(p=.16)$, very similar to the effect size of the 34 others studies of antisocial populations that did yield a significant effect size of $d=-.62$. It is likely that the small number of studies of psychopaths resulted in lack of power and failure to document statistical significance of this effect.

Since this meta-analysis, there has been further support for reduced frontal functioning in psychopaths. Prehn et al. (2013) found that emotionally hypo-reactive offenders with psychopathic traits showed reduced prefrontal functioning when regulating their behavior to choose "safer" alternatives in a task, and also showed diminished rostral anterior cingulate cortical activation in response to uncertainty. Psychopaths also show reduced activation in the ventromedial prefrontal cortex, when viewing emotional expressions and people being hurt (Marsh et al., 2013; Decety, Michalska, \& Akitsuki, 2008). 
Some studies hint at subtleties in results as well as null findings. For example, Bjork, Chen, and Hommer (2012) found that activity in the anterior cingulate cortex and the middle frontal cortex during reward anticipation was positively correlated with PPI (Psychopathic Personality Index, a measure of psychopathy) scores. This indicates a heightened sensitivity to rewards. Furthermore, beyond mere impaired functioning in the brain area itself, at least one study has suggested that reduced functional connectivity, like the structural connectivity identified by Craig et al. (2009), may play an important part in psychopathy (Motzkin, Newman, Kiehl, \& Koenigs, 2011). They found reduced functional connectivity between the ventromedial prefrontal cortex and amygdala, and ventromedial prefrontal cortex and anterior temporal lobe. A distinctively contradicting study (Muller et al., 2003) used fMRI and found that psychopaths, when viewing negative images (e.g. wounded people, threatening faces), showed increased activation in prefrontal regions (and the amygdala), whereas positive contents resulted in reduced activation in the right medial frontal and medial temporal regions.

Overall, as with structural imaging, fMRI studies generally trend in the direction of reduced frontal functioning in psychopaths. There are nevertheless context-related nuances in findings that cannot be ignored and make it difficult to draw firm conclusions. Future studies such as the passive viewing one conducted by Muller et al. (2003) would be helpful in identifying specific circumstances in which the psychopathic brain functions differently to controls.

\section{Adolescents with Callous-Unemotional Traits}

Understanding of the etiology of psychopathy is an ongoing process, but increasingly in recent years, attention has turned towards its development by looking at the children who may 
grow up to become psychopaths (e.g. Barry et al. 2000). Children and adolescents with disruptive behavioral disorders (DBD), such as conduct disorder (CU) or oppositional defiance disorder (ODD) have been a population of interest as possible "psychopaths in the making." More recently, these children have been recognized as heterogeneous, with a specific subset displaying high levels of callous-unemotional (CU) traits and who exhibit particularly aggressive and stable trajectories of antisocial behavior (Frick, 2009), a pattern similar to adult psychopaths (also Kahn, Frick, Youngstrom, Findling, \& Youngstrom, 2012). Relatively pessimistic views of treatment possibilities for adult psychopaths (e.g. Harris \& Rice, 2006) have led to a refocusing on a perhaps less refractory population, DBD children with CU traits (Anderson \& Kiehl, 2014).

Research has used the same brain imaging techniques (i.e. functional MRI, structural MRI) to parse neural abnormalities in such adolescents and children (Marsh et al., 2013). Identifying abnormal neural substrates and at what time point those abnormalities develop could in theory better inform treatment, and could change current juvenile adjudication processes. There is a fairly large body of neural imaging research on CD children (e.g. Huebner et al., 2008, Fairchild et al., 2013), but much fewer on the subset of DBD children with CU traits. In the context of the review below, it must be borne in mind that this is a recent and developing field, and as such firm conclusions cannot as yet be drawn.

\section{Amygdala}

The most consistent findings, with few exceptions, is that the amygdala in psychopathiclike adolescents echoes the functional deficiencies of the amygdala in adult psychopaths. Adolescents with conduct problems and callous-unemotional traits show less amygdala 
responsiveness to fearful faces (but not other emotional expressions) compared to healthy controls (Marsh et al., 2008; Jones, Laurens, Herba, Barker, \& Viding, 2009; White et al. 2012; Lozier, Cardinale, VanMeter, \& Marsh, 2014) and compared to children with conduct problems but low callous-unemotional traits (Viding et al., 2012). Several studies have used other methods to measure emotion processing and interpretation (Sebastian et al., 2012; Marsh et al., 2013). Sebastian et al. (2012) showed story panels with cartoon characters, and asked the subjects to infer how a story character would react to their companion's affective state based on the story line. CU traits were significantly and negatively associated with amygdala response to these affective scenarios while conduct problem symptoms were positively associated. Marsh et al. (2013) used photographs of pain-inducing injuries as stimuli, and asked subjects to either imagine the pain happening to themselves or to others; reduced activation in the amygdala was associated with higher psychopathic traits.

In contrast to functional imaging, there have been null findings regarding the structural integrity of the amygdala in children with CU traits (Wallace et al. 2014; De Brito et al., 2009). While Wallace et al. (2014) did find reduced amygdala volumes in children with CD, no effects were found for CU traits. Similarly, Fairchild et al. (2013) note reduced amygdala gray matter volume in adolescents with $\mathrm{CD}$, but no significant differences associated with CU traits.

Overall, studies on structural integrity of the amygdala are currently too few to draw firm conclusions. In contrast, the more robust finding to date in this area is amygdala hypoactivity when processing emotional or empathy-inducing stimuli in psychopathic-like children and adolescents. Impaired empathy and/or facial expression recognition are both risk factors for antisocial behavior (Shirtcliff et al., 2009; Blair, 2003) and also bear on the core features of callous-unemotional traits. What has not been addressed in the literature is whether amygdala 
under-responsivity predisposes to callous-unemotional traits, or alternatively whether these traits result in down-regulation of the amygdala and have a different etiology.

\section{$\underline{\text { Prefrontal Cortex }}$}

The literature based on the prefrontal cortex and its role in psychopathy in children and adolescents is just beginning to develop, with a particular scarcity of structural MRI studies. Two studies found that psychopathic incarcerated adolescents had decreased grey matter volumes in the orbitofrontal cortex (Ermer et al., 2012; Cope, Ermer, Nyalakanti, Calhoun, \& Kiehl, 2014). In contrast, De Brito et al. (2009), found increased grey matter concentration in the medial orbitofrontal cortex (and anterior cingulate cortex) of boys with elevated CU traits. This finding led De Brito et al. (2009) to note that normal cortical maturation involves grey matter loss, and consequently their finding of increased grey matter in their juveniles may reflect a delay in prefrontal maturation. Indeed, because an inherent and unique quality of juvenile brains compared to adults is their ongoing maturation, De Brito's (2009) theory is one that would not necessarily appear in the adult literature.

Functionally, Finger et al. (2008) showed abnormal ventromedial prefrontal functioning during probabilistic reversal tasks in youths (aged 10-17) with psychopathic traits. Reversal learning tasks require the subject to switch a response once a previously reinforced, rewarded response to a stimulus is no longer reinforced. Reversal errors refer to continuing to choose the first reinforced response, rather than switching over to the newly reinforced response. Analysis of the functional MRI results demonstrated that during punished reversal errors, children with psychopathic traits showed increased activity bilaterally in the medial frontal gyri. This shows that psychopathic traits are associated with abnormal processing of reinforcement information. 
White et al. (2013) found abnormal ventromedial prefrontal cortex functioning in CD children during a decision making task, but found no differences between subjects with high or low CU traits. Finger et al. (2011) compared teenage subjects with DBD disorders (mean age $=14.1$ years) to healthy controls (mean age $=13.1$ years) and found hypoactivity in the orbitofrontal cortex in response to early stimulus-reinforcement exposure and rewards. The psychopathic teens thus demonstrated reduced neural activity during the portion of the task when it was necessary to form stimuli-reinforcement associations, and also when they completed the task correctly, and were thus "rewarded."

Overall, structural and functional impairments to the ventromedial prefrontal cortex and the orbitofrontal cortex have been documented in adolescents with callous-unemotional traits. The lack of consistent trends in adolescents, perhaps more so than in adults, may either reflect neurodevelopmental processes which are more ongoing in adolescents compared to adults, or alternatively may reflect the reality that callous-unemotional traits in adolescents are only part of the larger constellation of traits that are used to measure adult psychopathy, and this comparison of findings across these age-groups are not strictly comparable.

\section{Summary of Imaging Findings in Adolescents and Adults}

With some exceptions, the majority of studies to date have demonstrated reduced function, volume, and connectivity in the frontal cortex and the amygdala in psychopathic adults and adolescents, two brain areas strongly implicated in prosocial behavior and moral decisionmaking. The amygdala is an important paralimbic structure that is necessary for emotion recognition (particularly negative emotions), and fear conditioning — two areas in which 
psychopaths have been shown to be deficient. Impaired amygdala functioning and structure would lead to antisocial behavior because cues such as fear of punishment, or aversion to causing fear/pain are not felt as deeply. The prefrontal cortex is implicated in a number of functions that, if impaired, would have significant influence on tendency towards antisocial behavior, including executive functioning, impulse control, moral decision-making, reward and punishment processing, behavioral inhibition, and planning for the future. Lesion studies from neurology strengthen the hypothesis that structural damage to the ventral prefrontal cortex leads to acquired symptoms of sociopathy (Barrash, Tranel, \& Anderson, 2000; Bechara, Tranel, \& Damasio, 2000; Young et al., 2010), which in turn suggests that the correlation between psychopathy and prefrontal cortex impairments found in brain imaging studies is consistent with a causal model.

The topic of children with psychopathic-traits is a controversial one, given the stigma associated with the label. Based on neuroimaging findings, there is support for extending the psychopathy construct into juveniles. Like adults, the prefrontal cortex in juveniles with high $\mathrm{CU}$ traits demonstrates reduced structural integrity and functioning. Despite null structural findings in the few studies conducted to date, significant functional deficits have been documented. The presence of neural abnormalities in children with psychopathic traits validates the notion that the construct of psychopathy can be extended into adolescents, and even young children.

There is little question that a growing body of basic science imaging research is documenting brain differences in adult psychopaths, and as noted above, increasingly in psychopathic-like adolescents. The challenge arises in sensibly evaluating whether this knowledge could or should receive application within the criminal justice system - now or in the future. The next section aims to address this controversial issue with respect to how such 
imaging data might be used to predict future offending, modify our retributivist perspective on offenders, and even result in new treatment approaches.

\section{Punishment, Prediction, and Intervention: Implications for Criminal Justice}

Due to high recidivism rates, repeat interactions with the criminal justice system, heightened violent behavior, and research indicating little effective treatment for adult psychopathy, this sub-group of offenders provide significant practical and theoretical challenges for the criminal justice system. Unfortunately, the characteristics and interpersonal and affective deficits of psychopathy often contribute to severe and persistent offending behavior (SearaCordoso \& Viding, 2014), resulting in lingering questions for the criminal justice system on how to effectively handle, address and prevent psychopathic offending. Correspondingly, research concerning functional and structural neural deficits of psychopaths in brain areas directly involved in emotion recognition, decision-making, morality, and empathy, has generated dialogue on the means by which this research on psychopathy may inform, affect, and influence many questions and challenges for the criminal justice system. These issues include the role and use of brain imaging evidence in court, possible effects on perceptions of an adult psychopath's moral and legal responsibility or punishment, how this research may inform assessments of dangerousness and risk, and how traditional punishments may be ineffective for adult psychopaths.

As this review has tentatively established that adult and juvenile psychopaths exhibit similar neural deficits, it is likely that this existing dialogue can inform similar discussions relevant to juvenile psychopathic offenders. There has been significant discussion surrounding how this neural research may influence conceptions of adult psychopathic offending, but there has been less on its possible implications for juvenile psychopathic offending. Thus, the research 
included in this paper is potentially most impactful in discussing possible implications for the punishment, prediction and possible methods of intervention concerning juvenile psychopathic offenders in the criminal justice system. After briefly reviewing the literature on how brain research potentially affects, aids or informs the punishment, prediction, and possible interventions for adult psychopathic behavior, implications for juvenile psychopathic offenders in these same areas of the criminal justice system will be discussed, a review structure adopted from Glenn and Raine (2014).

\section{Adult Psychopaths in the Criminal Justice System}

\section{Punishment}

In general, research on the punishment and sentencing of adult psychopaths has shown that they often receive harsher, longer and more retributive sentences than other offenders (Medina \& McCranie, 2010; Gazzaniga, 2011). They are often seen as much more dangerous and violent than other offenders, highly likely to recidivate, and unable to be treated, which can have significant effect on the legal decisions rendered to them (Lyon \& Ogloff, 2000; Skeem et al., 2011). Yet, some scholars have argued that brain research on this disorder has demonstrated that these traditional, harsher punishments for psychopathic offenders may be ineffective and obsolete for several reasons (Aharoni et al., 2007; Morse, 2008).

First, it has been thought that psychopaths are less able to associate their actions with related punishment and are less sensitive to punishment (Fowles, 1980; Lykken, 1995). As shown above, research has demonstrated that psychopaths have structural and functional impairments to the prefrontal cortex, including the ventromedial prefrontal cortex, and the amygdala, both involved in the normal development of punishment association and reward and punishment processing (Baxter \& Murray, 2002; Wallace et al., 2014). This potentially provides 
evidence that psychopaths may be not be deterred from offending or reoffending by severe punishments due to these impairments. Thus, traditional punishments may not be effective for psychopathy because psychopaths are insensitive to the idea of retribution (Aharoni et al. 2007). This also connects to past findings indicating that retributive attitudes often foster cooperative and prosocial behavior (Boyd \& Richerson, 1992; Fowler, 2005; Kurzban et al., 2007), tendencies which psychopaths do not exhibit.

Second, psychopaths are impaired in moral judgment. Research has illustrated that adult psychopaths have functional and structural neural impairments in regions involved in normal moral processing and decision-making, and empathy (Pridmore, Chambers, \& MacArthur, 2005; Glenn, Raine \& Schug, 2009; Yang et al., 2009). This has led some scholars to conclude that due to these deficits and the incapacity to understand and act according to moral reasons, "severely" psychopathic individuals are inherently incapable of formulating moral responsibility for their actions and understanding the moral principles of criminal law (Levy, 2007; Morse, 2008). Therefore, traditional punishment is obsolete and they should not be legally blamed or punished for their behavior in the justice system (Levy, 2007; Morse, 2008; Glenn, Raine, \& Laufer 2011). Glenn, Raine and Laufer (2011) argue, instead, these individuals should be handled by other forms of social control, such as involuntary civil commitment (Morse, 2008). There have also been questions as to whether less "severe" psychopaths should also be excused in the ways discussed above. Morse (2008) argues different jurisdictions would have to make decisions on a case-by-case basis on whether individuals considered "less severe" psychopaths should be traditionally adjudicated and sentenced. He suggests some "less severe" psychopaths would still be "subject to blame and punishment" (Morse, 2008). 
However, other literature, although acknowledging the incapability of psychopaths to properly formulate or understand moral responsibility, has argued that psychopaths are still criminally responsible for their acts and should be accordingly adjudicated and punished within the criminal justice system irrespective of the cause of their moral incapacitation (Levy, 2011). Thus, there is a lack of consensus regarding to what degree psychopaths are legally or morally culpable for their behavior and what types of punishments or social control should be utilized.

Evidence concerning neural abnormalities and processing deficits identified in psychopaths and its role, relevance, and use in the courtroom has also created discussion and divided opinion. This evidence is often described as a "double-edged" sword (Barth 2007), meaning evidence can seen as either a mitigator or aggravator when determining level of responsibility and corresponding sentence for offenders in court. Nevertheless, robust data on exactly how this type of evidence has been used in court as a mitigator or aggravator do not exist (Morse \& Newsome, 2013), and imaging data in capital cases is almost always brought in by the defense, and rarely if ever by the prosecution (Kolla \& Brodie, 2012). However, in non-capital cases, judges are not usually guided by legal doctrine on the types of evidence that should be considered either aggravating or mitigating. They are also not guided on how much weight should be put on brain or neuroimaging evidence (Morse \& Newsome, 2013). In capital cases, juries do have guidelines regarding mitigating or aggravating factors, but they are often ambiguous (Morse \& Newsome, 2013). Thus, courts are often left to interpret what constitutes either mitigating or aggravating evidence.

As a mitigator, evidence of neural abnormalities may be presented to identify or explain the underlying reasons for or origins of behavior, and to demonstrate that this behavior is out of the individual's control due to the biological abnormalities (Monterosso, Royzman \& Schwartz, 
2005). This may potentially reduce punishments defined as retributive in nature, as one would be found to be in less control of one's behavior and therefore less culpable for one's corresponding actions. As an aggravator, evidence of neural impairments may be presented to portray an individual as unchangeable due to the biological abnormalities, and therefore, dangerous and likely to recidivate (Snead, 2007). This would potentially increase utilitarian punishments aimed at the safety of the community, as one would be found inherently dangerous, untreatable, and therefore should be incapacitated or regulated for the welfare of the public (Aspinwall et al., 2012).

To assess these principles surrounding psychopathy, Aspinwall, Brown, and Tabery (2012) studied the effect of evidence concerning genetic factors, abnormal brain development, and amygdala dysfunction of psychopathy on the severity of punishment rendered by U.S. state trial judges and the judges' classification of psychopathy as an aggravating factor. Findings showed that before the evidence was presented, judges rated an individual's psychopathy as an aggravating factor. However, the presentation of biomechanism evidence surrounding psychopathy significantly reduced sentencing severity and the extent to which judges classified psychopathy as an aggravating factor in their sentencing decisions (Aspinwall et al., 2012). Similar to discussions about degrees of moral and legal responsibility for psychopaths, one judge who viewed the evidence as a mitigating factor commented, "The evidence that psychopaths do not have the necessary neural connections to feel empathy is significant. It makes possible an argument that psychopaths are, in a sense, morally 'disabled' just as other people are physically disabled. I have received and considered such evidence in past trials" (Aspinwall et al., 2012, p. 847). These findings demonstrate that at least in some instances, biological evidence on psychopathy does have the ability to affect and mitigate traditionally harsh or "aggravated" 
sentences of psychopaths, and some judges do consider the abnormalities of neural structure and processing in psychopaths as they relate to emotional and moral deficits as a persuasive and mitigating factor in their sentencing of these individuals.

The literature has also covered the possible use of brain imaging evidence in cases involving adult psychopathic offenders. Although courts have regularly allowed the presentation of brain imaging data, specifically CT, MRI, PET, and SPECT evidence, as related to neuropathology or proof of brain injury in some criminal cases, its use has been far rarer in cases where the evidence is used in responsibility determination or sentencing in an attempt to explain the underlying reasons for an antisocial or criminal act (Moriarty, 2008). Courts are still debating the relevance and role of this data in the courtroom, whether it should be admissible, and how it could adversely affect jury or judge decision-making (Farah, 2004; Mobbs, Lau, Jones, \& Frith 2007; Fabian, 2010).

Even so, brain imaging evidence demonstrating structural and functional impairments in regions involved in impulse control, emotional processing, morality, empathy and other behaviors, such as those exhibited in psychopathy, does generate significant questions regarding the moral responsibility of adult offenders and has the potential to make useful contributions to legal decision-making (Yang, Glenn, \& Raine, 2008; Fabian, 2010). Glenn and Raine (2009) argue if properly presented, neuroimaging data could be valuable and informative in some cases, including those involving psychopathic offenders, in the future. Yet Glenn and Raine (2009) also agree with the consensus view that brain-imaging evidence should be handled and utilized carefully and appropriately, and that at the current time, brain imaging may currently lack the levels of diagnostic and predictive accuracy required by the legal system. Yet, that also creates the scientific and legal question of how much neuroimaging evidence will be required in order to 
meet these thresholds for appropriate use in the legal system. Thus, it is crucial for the criminal justice system to fully understand the limitations of the evidence before its use (Mobbs, Lau, Jones, \& Frith, 2007).

$\underline{\text { Prediction }}$

Although there has been some debate on the ability of psychopathy to effectively predict offending (Coid, Ullrich, \& Kallis, 2013), the literature has largely indicated that scores on psychopathy assessments predict both violent and non-violent offending, albeit imperfectly (Kiehl \& Hoffman, 2010; Richards, Casey, \& Lucente, 2003; Cornell et al., 1996; Harris, Rice \& Cormier, 1991). As psychopathy recidivism rates are high, there have been calls for the dedication of resources and research on how neural correlates and deficits associated with psychopathy may be able to aid in creating even more accurate and effective predictive tools and measures for violence and recidivism of psychopathic offenders in the future (Nadelhoffer et al., 2010).

Two brain imaging studies have documented proof of concept that brain imaging may in the future aid prediction of offending. Pardini at el. (2014) documented that high-risk community males with reduced amygdala volumes at age 26 were three to four times more likely to commit a violent act three years later. Aharoni et al. (2013) found that released prisoners with reduced activity in the Anterior Cingulate Cortex (ACC) were twice as likely to recidivate over a four year span compared to released offenders with high ACC activity. Both studies showed predictive utility from brain imaging data over and above prior history of violence, psychopathic behavior, and other non-brain predictors of violence. No study to date however has shown the long-term predictive utility of brain imaging data with respect to offending in juveniles. 
Kiehl (2006) has argued that the identification of neural deficits associated with psychopathy, especially in the paralimbic system, may be as effective as identifying risk factors in traditional assessments and measures of psychopathy. Further, Glenn and Raine (2009) have argued that the neural deficits related to psychopathy should be considered risk factors, likened to other psychological and social factors for antisocial or criminal offending. Current risk assessment tools, which evaluate different risk factors to estimate the risk of future offending, are widely used in the criminal justice system, but the overall predictive accuracy of these actuarial risk assessment instruments has been widely debated (Hart, Michie, \& Cooke, 2007; Yang, Wong, \& Coid, 2010; Fazel et al., 2012). Generally across instruments, it has often been reported that the positive predictive value of these instruments is no better than chance (Hart, Michie, \& Cooke, 2007; Fazel et al., 2012). Nevertheless, some evidence suggests that instruments for assessing violent offending may have better predictive power compared to tools for general or sexual offending, although their accuracy has only been noted at a low to moderate level (Yang, Wong, \& Coid, 2010; Fazel et al., 2012). Researchers therefore caution that assessments with low to moderate levels of predictive accuracy should not be used as sole evidence in legal decision-making, but rather in conjunction with other types of evidence (Yang, Wong, \& Coid, 2010). Thus, as current tools are seen as imperfect predictive measures for offending, considering neural deficits related to psychopathy as risk factors for offending (Kiehl, 2006; Glenn \& Raine, 2009), could be helpful additional evidence for the criminal justice system and courts to utilize, along with existing tools, in order to more effectively assess and make decisions regarding an offender's risk of future offending.

Currently, risk assessment instruments are not generalized across jurisdictions (Schwalbe, 2007), and there is wide variability regarding the consistency in which they are used, if at all. 
Variability also exists in the types of instruments utilized and what sources of information are used during risk assessments. However, when used they are most frequently utilized by judges using assessments of risk in probation and sentencing decisions and guidelines. Judges, in consultation with probation, corrections and other areas of the criminal justice system, determine the format and content of risk assessment information used in court. This often includes measurements of pro-criminal attitudes, social supports for crime, antisocial personality patterns, substance abuse, family and marital relationships, and involvement in social, work, and school activities (Bonta \& Andrews, 2007). Overall, researchers believe that current research on the neural abnormalities of psychopathy is at too early a stage for judges and other members of the criminal justice system to effectively or properly integrate it into these existing methods and models of prediction and risk assessment in the criminal justice system (Gazzaniga, 2011). Nevertheless, researchers do express optimism that this research could be one day helpful for aiding risk assessment and in prediction (Gazzaniga, 2011).

Intervention

Although there has been some discussion about the possible efficacy of adult psychopathy treatment interventions, by and large there is limited evidence that current treatment interventions for adult psychopathy are successful (Cleckley, 1988; Hare, 2003; Harris \& Rice, 2006), and some have argued that some interventions can potentially exacerbate psychopathic tendencies (Harris \& Rice, 2006). Yet, researchers believe brain research on psychopathy may be able to inform possible treatment modes in the future (Mobbs, Lau, Jones, \& Frith, 2007; Glenn \& Raine, 2009).

For example, Glenn and Raine (2009) discuss the possibility of one day being able to modify or remedy the function of deficits of affected brain areas in psychopaths, 
pharmacologically, hormonally, or through behavioral therapy. Repetitive transcranial magnetic stimulation (rTMS) has also been discussed as a potential non-invasive treatment method to alter brain function in psychopaths (Glenn \& Raine, 2009; Canavero, 2014; Maibom, 2014) and recent initial studies on transcranial direct-current stimulation (tDCS) appears to affect risk-taking, moral decision-making, and feelings of guilt (Fecteau et al., 2007a; Fecteau et al., 2007b; Boggio et al., 2010; Karim et al., 2010). Based on initial research (Ruff, Ugazio, \& Fehr, 2013) showing that right lateral prefrontal stimulation using tDCS enhanced compliance to social norms enforced by punishment (an analogue to law-abiding behavior), Glenn and Raine (2014) have suggested tDCS has potential implications for crime prevention, and as such may be relevant to the potential treatment of psychopathy.

Overall, psychopathy researchers have voiced both optimism and pessimism, but mostly ambivalence, on the likelihood that neuroscience research on psychopathy will ever be able to aid in creating an effective treatment for psychopathy (Glenn \& Raine, 2009). What could change that ambivalence is future advances in the treatment and prevention of psychopathic-like behavior in juveniles, a subject group to now which we turn.

\section{Juvenile Psychopathy in the Criminal Justice System: Implications}

Moving forward, the research included in this paper, informed by the previous literature on adult psychopathy in the criminal justice system, raises numerous possible issues for handling youth offenders in the criminal justice system. Specifically, there are several potential implications for the punishment, prediction and possible methods of intervention concerning juvenile psychopathic offenders.

\section{Punishment}


Research on the deficits and neurological abnormalities of juvenile psychopaths could possibly act as a "double-edged sword" to punishment and sentencing of juvenile offenders, as well as indicate the futility of traditional punishments on this population. Similar to adult psychopaths, juvenile offenders who have been described or labeled as psychopathic have also received harsher and more punitive sentences (Sharp \& Kine, 2008). Labeling juvenile offenders as psychopaths has often led to the assumption that they pose a greater risk of reoffending and higher risks of violence in the future (Boccaccini et al., 2008), as the label creates the assumption that youth with psychopathic traits are just as unresponsive to treatment or intervention as adult psychopaths (Seagrave \& Grisso, 2002). Therefore, treatment or other interventions may be denied to youth offenders with psychopathic tendencies and have possible ill effects on sentencing (Book, Clark, Forth, \& Hare, 2013).

As psychopathy is seen as an aggravating factor for both adult and youth offenders, research indicating inherent neural and processing deficits in juvenile psychopathic offenders could potentially mitigate the label as well as the severe punitive sentences often administered to psychopathic offenders, as it was shown to do for adult psychopaths in Aspinwall et al. (2012). Depending on the receptiveness of a judge or a jury, this type of scientific evidence may indicate that the offender is incapable of normal moral and emotional processing due to these biological abnormalities, and therefore, is less responsible and blameworthy for their behavior. However, this research could also exacerbate existing harsh punitive sentences bestowed upon juvenile psychopathic offenders. Similar to how research of this sort could be used as an aggravating factor in the trials of adult offenders, evidence on neural abnormalities may be used to portray juvenile psychopathic offenders as more inherently dangerous or immutable and, therefore, unable to be treated or helped. This would increase the likelihood of even more severe utilitarian 
punishments that aim to safeguard the welfare of the public, such as long incapacitation sentences in order to remove the threat from society.

Neural and cognitive research on juvenile psychopathic offenders also solicits questions on the effectiveness of traditional punishments for these youth offenders. This review has shown that youth with psychopathic tendencies, like adult psychopaths, have structural and functional impairments to the prefrontal cortex and the amygdala. They have been found to also exhibit punishment insensitivity and difficulties in stopping reward-seeking behavior even when there is a high likelihood of severe or harsh punishment associated with the reward (Dadds \& Salmon, 2003). Thus, juvenile psychopathic offenders may also be insensitive to traditional retributive sentences and not be deterred by severe punishment, similar to adult psychopaths. This insensitivity to traditional discipline to control behavior has been shown, at least on a low level outside of the criminal justice system, to be true for children with CU traits who "act out" (Viding, Fontaine, \& McCroy, 2012), as well as the lack of success for punishment-oriented strategies to stop or remedy behavior associated with psychopathic tendencies (Salekin, 2002; Caldwell et al., 2007).

Therefore, alternative sentencing or methods of social control may be more effective for youth offenders with brain impairments and psychopathic tendencies than traditional punishments, as they have been suggested for adult psychopathic offenders (Glenn, Raine, \& Laufer, 2011; Morse, 2008). Although research is inconsistent, there has been some discussion about the potential effectiveness on the reward-oriented behavior of youth with psychopathic tendencies to promote, encourage and reward pro-social behavior instead of punitive or disciplinary methods (Viding, Fontaine, \& McCroy, 2012; Frick et al., 2014). Other research has suggested that intensive interventions specifically tailored to the behavioral problems of 
individual youth with elevated callous-unemotional traits may be effective (Frick et al., 2014).

Moving forward, alternative sentencing methods, such as interventions that stress rewarding prosocial behavior and cooperation rather than punishment-oriented sentences, could be useful for youth offenders with psychopathic tendencies in attempts to change behavior. However, the criminal justice system is currently far off from being able to provide those types of services to youth offenders.

Although the broad consensus is that it may be too early to effectively and appropriately use brain imaging evidence in criminal trials to address the issue of legal responsibility as the law currently stands, it may one day have the potential to make useful contributions to legal decision-making in cases involving adult psychopaths (Yang, Glenn, \& Raine, 2008; Fabian, 2014). However, its use in criminal trials involving juvenile psychopathic offenders brings in issues that may not be relevant to trials involving adult psychopaths. One such issue concerns findings that have indicated that the prefrontal cortex - which is implicated in impulse control, risk taking, decision-making, and many other risk factors for antisocial behavior - in normal juveniles continues to rapidly develop and mature after the age of 18 and well into an individual's 20's and 30's (Giedd, 1999; Sowell et al., 2001). Therefore, the argument is that juveniles may not be able to exercise the same level of decision-making or impulse control as that of adults until their brains have fully matured. This research has aided the overturning of the death penalty for juveniles in 2005 (Roper v. Simmons 2005).

At the same time, structural and functional deficits of the prefrontal cortex are also impairments exhibited by juvenile psychopaths. One may imagine that if brain imaging data on the prefrontal cortex were introduced as evidence in a trial involving a juvenile psychopathic offender in an attempt to show impairments to decision-making or impulse control due to 
psychopathy, it would be very difficult, if not impossible, for juries and judges to identify what neural characteristics may be causally connected to psychopathy or may just be related to normal brain development as an adolescent. In either case, the evidence could be used to argue that an offender's decision-making and moral thinking are impaired. However, if jurors or judges believe that neural characteristics are caused by psychopathic behavior, rather than normal adolescent brain development, that may affect their decisions on sentencing or attitudes towards treatment alternatives.

Similar to concerns surrounding DNA evidence and other technical scientific evidence (Hans, 2007), there are already worries about the abilities of juries and judges to understand brain-imaging data and appropriately and effectively utilize it in their decision-making (Farah, 2004; Mobbs, Lau, Jones, \& Frith, 2007; Fabian, 2010). Judges and, particularly, juries often have trouble making statistical inferences from scientific evidence, such as understanding falsifiability and error rate, which in turn could undermine their decision-making (Gatowski et al., 2001; Kaye et al., 2007). The use of this data in trials involving juvenile psychopathic offenders would likely add an additional burden to these existing concerns.

The counter-perspective is that understanding error rates is inherent in the risk assessments that occur all the time in courts, and that imaging research is no more complex than some other areas of forensic science brought into the courtroom by expert witnesses. As the public are becoming increasingly familiar with brain imaging in newspapers, magazines, and even TV, and as the judiciary become increasingly familiar with the strengths and limitations of neuroscience through seminars organized by AAAS, the MacArthur Foundation, and state-wide judicial educational institutes, using brain imaging to obtain objective information on brain 
maturity and cognitive/emotional capacity could become no less important than having an IQ test to help assess intellectual disability.

$\underline{\text { Prediction }}$

Regarding prediction, the research reviewed in this paper is likely most applicable to discussions surrounding the utility of juvenile psychopathy for anticipating future offending in two main areas: offending in adulthood (after the age of 18) and offending later in adolescence and before adulthood (age 18 or younger). In most states, an offender age 18 or younger is legally considered a juvenile offender.

For offending in adulthood, the current literature demonstrates uncertainty on whether identifying neural deficits and psychopathic tendencies in juvenile psychopaths may be useful or effective in the long-term prediction of psychopathic behavior and offending after the age of 18. On one side, some research has argued that the neural deficits and behaviors of juvenile psychopaths are stable, long-term factors that lead to adult psychopathic behavior and offending (Loney et al., 2007; Pardini et al., 2014; Anderson \& Kiehl, 2014). Since juvenile psychopaths share many of the same neural deficits and personality characteristics documented in adult psychopaths, as suggested by this review, many have reported that the deficits and behaviors of juvenile psychopathy should be considered a developmental antecedent to adult psychopathy (Barry et al., 2000; Lynam et al., 2005; Lynam et al., 2007; Frick, 2009). On the other side, many recent studies have concluded that assessments of juvenile psychopathy have been largely ineffective in predicting adult psychopathic offending (Cauffman, Kimonis, Dmitrieva, \& Monahan, 2009; Edens \& Cahill, 2007; Stockdale, Olver, \& Wong, 2010; Gretton et al., 2004) and many individuals who exhibit psychopathic tendencies as children do not exhibit these 
tendencies in adulthood (Lynam, Caspi, Moffitt, Loeber, \& Stouthamer-Loeber, 2007; Skeem et al., 2011).

Although there is little consensus on how juvenile psychopathy may anticipate psychopathic behavior and offending after the age of 18 , both sides of the literature have implications for juvenile psychopathic offenders within the criminal justice system. If juvenile psychopathy, and corresponding neural abnormalities and processing, provides long-term prediction with acceptable accuracy of adult psychopathic behavior and criminal offending, then judges or juries adjudicating youth offenders with psychopathic tendencies may view or label them as "life long" psychopaths, rather than juvenile offenders. They may believe that these offenders are beyond help, similar to adult psychopaths, and solely focus on punitive sentences and incapacitation in order to prevent adult future offending (Lyon \& Ogloff, 2000; Skeem et al., 2011). On the other hand, if juvenile psychopathy does not predict either psychopathy or offending in adulthood, juvenile psychopathic offenders may be less likely to be perceived or labeled, as they are currently, as inherently dangerous or not amenable to treatment (Book, Clark, Forth, \& Hare, 2013). These views could affect the type and severity of the sentence, as individuals may be much more open to sentencing alternatives for these offenders, including treatment interventions. Juveniles would also be less likely to be transferred to adult courts (Skeem et al., 2011), as it would be unclear if these behaviors or reoffending would continue into adulthood.

However, in cases of juveniles offending later in adolescence, there is general support that the presence and assessment of psychopathic tendencies in juveniles has been shown to be effective in short-term prediction of offending and recidivism at age 18 or younger (Edens \& Campbell, 2007; Edens, Campbell, \& Weir, 2007; Stockdale, Olver, \& Wang, 2010; Asscher et 
al., 2011). Asscher et al., (2011) argues that recidivism for juvenile psychopathic offending before the age of 19 can be predicted at around age 10 to 12 . So although it is unclear if it is an effective predictor for long-term offending in adulthood after the age of 18 , it appears juvenile psychopathy does provide an effective measure for predicting future offending and recidivism before the age of 19. Therefore, identifying neural deficits and psychopathic tendencies in juvenile psychopaths could be useful or effective in predicting offending of individuals in that age range.

Intervention

Recognizing that juvenile psychopathy does to some extent predict the likelihood of future offending in adolescence, identifying ways to treat or intervene in psychopathic behavior early in childhood or youth may possibly prevent years of offending as a juvenile before adulthood. Research on the neural abnormalities and deficient processing of juvenile psychopathy could potentially aid in further clarifying the etiology of psychopathy and identifying potential treatment interventions for juvenile psychopaths. Some possible future treatment interventions that have been discussed for adult psychopathy (Glenn \& Raine, 2009; Canavero, 2014; Maibom, 2014; Fecteau et al., 2007a; Fecteau et al., 2007b; Boggio et al., 2010; Karim et al., 2010) have the potential to be effective for juvenile psychopathy as well.

Yet perhaps most promisingly, recent research has demonstrated that omega-3 essential fatty acids supplementation could be an effective treatment intervention for improving youth psychopathic behavior in the long-term. Omega-3 has been known to be important for healthy brain development in children (Ryan et al., 2010; Schuchardt et al., 2010) and low levels have been implicated in poor cognitive performance and behavior in children (Montgomery et al., 2013). Poor nutrition during pregnancy and early childhood, including lower levels of omega-3, 
has been thought to negatively affect brain structure, function, and is associated with later antisocial behavior in adolescence and adulthood (Raine, 2008; Liu, 2011).

Recently, Raine et al. (2014) reported findings from a randomized controlled trial showing that omega-3 supplementation results in long-term improvement in callous-unemotional traits in 8-16 year old children six months after the treatment ended. Furthermore, the parents of children receiving omega-3 supplementation showed a significant long-term reduction in their own psychopathic behavior. This reduction in parental psychopathy partly accounted for the improvement in their children's' callous-unemotional traits (Raine et al., 2014). As high levels of callous-unemotional traits are the defining measure of psychopathic-like child behavior and forms the basis of what is presently known about the presence and development of juvenile psychopathy, these results if replicated and generalized to other populations suggest that omega3 interventions could conceivable prevent the development of adolescent psychopathy, and possibly provide an alternative option for treating juvenile offenders with psychopathic features.

Finally, in conjunction with other risk factors, research on neural deficits associated with psychopathy may one day help in identifying children who are at extreme risk for offending or future violence before entrance into the criminal justice system (Glenn \& Raine, 2009), either as a juvenile or as an adult. Many scholars agree that the treatment of psychopathic tendencies in youth may be more effective if addressed and detected early, especially before the behaviors have expressed themselves criminally (Anderson \& Kiehl, 2014; Salekin, 2002; De Brito et al., 2009; Cohn et al., 2013). Methods of possible early identification and interventions for children with psychopathic tendencies that have not yet entered the criminal justice system. In addition to providing interventions for juvenile psychopaths who have previously offended, such methods could potentially protect the public from both future adult and juvenile offending, as well help 
reduce the burden and cost to the criminal and juvenile justice systems for repeat adult and juvenile offenders. For example, the research on omega-3 supplementation above suggests that a dedication of resources for nutrition programs in schools or the subsidization of omega-3 supplements could potentially be effective in preventing and treating future antisocial and psychopathic behavioral traits in adolescents before they become expressed at an adult, criminal level.

\section{Recommendations for Future Research}

Although the adult psychopathy literature has established abnormalities to the amygdala and prefrontal cortex, the literature on DBD children with CU traits needs to be extended. The current literature is lacking in longitudinal neuroimaging studies of such subjects, and thus it is an open question as to whether the neural deficits apparent in youthful psychopaths continue to be present in adulthood. No study appears to have taken youthful psychopaths, measured functional and/or structural integrity of their brains, and then followed up with the same procedure in adulthood. Although Lynam et al. (2007) have begun the important effort of ascertaining the predictive power of youth psychopathy to adult offending, this is a relatively under-researched area that needs extension. It appears that there are two paths for these DBD children with CU traits. On the one hand, they could "outgrow" both their DBD, and their neural deficiencies. On the other hand, they could continue down the pathway to psychopathy. Carefully formulated future studies would be informative in fleshing out the developmental pathway of psychopathy.

What could be helpful in this regard would be expansion of the affective facet of psychopathy on the PCL-R and PCL-YV which currently consists of only four items (i.e., lack of remorse, shallow affect, callous/lacking empathy, and failure to accept responsibility). 
Otherwise, expanding use of instruments such as the Inventory of Callous-Unemotional Traits in future studies regarding children with DBD may help illuminate important differences within that heterogeneous group.

Increasing our understanding of the treatment of psychopathy is an important goal and the research base to date is relatively sparse. This may change. Brain imaging research is providing a new vista into psychopathy and criminal behavior, and such knowledge could potentially help stimulate a new approach to treatment. Attempting to address the neural deficiencies that appear in both adult and juvenile populations is beginning, and together with existing cognitive behavioral therapies could provide advances in both prevention and intervention. Psychopathic individuals are a specific subset of offenders with distinctive features, yet it remains to be seen if new biosocial treatment programs can be developed to ameliorate these specific features.

It must be recognized that the neurobiology of psychopathy is unlikely to be reduced to one or even two simple brain circuits centered on the amygdala and prefrontal cortex, but likely involves multiple brain dysfunctions and circuits that each give rise to different features of psychopathy. If so, there may be greater traction in brain research focused on specific traits of psychopathy, rather than on the more global psychopathy construct. As one example, the specific psychopathic feature of pathological lying and deception has been the focus of one study documenting increased prefrontal white matter in such individuals compared to both antisocial and normal control groups (Yang et al. 2005). Future research could usefully focus on other specific psychopathic features - for example grandiosity, irresponsibility, and lack of long-term planning - and widen the scope beyond the psychopathic traits of callousness and lack of empathy that are being increasingly researched. 
Finally, one greatly under-researched area that holds significant promise in bridging brain-imaging research with treatment research consists of incorporating biological measures into treatment programs for psychopaths and other offenders. This yields two different approaches. First, in a review of ten such studies of antisocial individuals using cognitivebehavioral therapy, neuropsychological, hormonal, and psychophysiological measures at baseline were predictive of treatment outcome (Cornet et al., 2013). This approach could help identify offenders particularly amenable to rehabilitation. Second, a review of 11 behavioral treatment programs for antisocial behavior documents changes following treatment in biological risk variables for antisocial behavior, an approach which helps to identify the mechanism of action underlying treatment change (Cornet, Kogel, Nijman, Raine, \& van der Laan, 2014). None of these studies included brain imaging measures, yet such future studies on psychopaths could significantly expand these two approaches and help move brain imaging research into the treatment arena.

\section{Conclusion}

This review documents that brain abnormalities, particularly structural and functional reductions in the amygdala and frontal cortex, have been found in both adult psychopaths as well as their juvenile counterparts. These implicated areas are considered key areas of the brain responsible for moral decision-making, affect processing, fear conditioning, and executive functioning. Correspondingly, both adults and juveniles who exhibit psychopathic traits demonstrate impaired impulse control, lack of guilt, poor empathy, fearlessness, insensitivity to punishment, and reward-seeking behavior. All such characteristics are risk factors that are in part predicated on the prefrontal and amygdala impairments observed in psychopaths, and help explain their recidivistic antisocial behavior. Current research also indicates relatively few 
effective treatment options for psychopaths, although this may change in the future. Thus, psychopathy raises question for the criminal justice system on how to effectively handle, address and prevent these offenders.

As psychopaths represent such a significant challenge for the criminal justice system, research concerning functional and structural amygdala and prefrontal deficits of adult psychopaths has spurred dialogue in recent years on if and how this brain research may be influential, beneficial or important in addressing adult psychopathic offending. Issues include how brain imaging evidence could be used appropriately in court, possible effects of these neural abnormalities on moral and legal responsibility and punishment, the potential use of neural deficits associated with psychopathy as risk factors for offending, and how this research may be helpful in the development of new treatment approaches. In the same realm, recognizing the emerging child and adolescent imaging literature documenting similar brain abnormalities to adult psychopaths, brain research additionally raises similar issues and implications for the punishment, prediction and possible methods of intervention for juvenile offenders in the criminal justice system.

The future promise of brain imaging research lies in providing new insights into the etiology of psychopathy that will help society navigate difficult decisions regarding the punishment, prediction, and prevention of these offenders. This is especially true of adolescents with psychopathic traits. Neurobiological research may ultimately become integral in informing methods to treat or intervene in psychopathic behavior early in childhood or adolescence, for example using nutritional interventions to change the brain to change behavior. Rather than accepting psychopathic individuals as immutable and untreatable, science and society should work to utilize neuroscience techniques to help develop innovative new treatment programs. 
Whether this future translational science promise can be truly achieved remains to be seen. 


\section{References}

Adolphs, R., Tranel, D., Damasio, H., \& Damasio, A. (1994). Impaired recognition of emotion in facial expressions following bilateral damage to the human amygdala. Nature, 372(6507), $669-672$.

Aharoni, E., Weintraub, L. L., \& Fridlund, A. J. (2007). No skin off my back: Retribution deficits in psychopathic motives for punishment. Behavioral sciences \& the law, 25(6), 869-889.

Aharoni, E., Vincent, G. M., Harenski, C. L., Calhoun, V. D., Sinnott-Armstrong, W., Gazzaniga, M. S., \& Kiehl, K. A. (2013). Neuroprediction of future rearrest. Proceedings of the National Academy of Sciences, 110(15), 6223-6228.

Anderson, N. E., \& Kiehl, K. A. (2014). Psychopathy: Developmental perspectives and their implications for treatment. Restorative neurology and neuroscience, 32(1), 103-117.

Aspinwall, L. G., Brown, T. R., \& Tabery, J. (2012). The double-edged sword: Does biomechanism increase or decrease judges' sentencing of psychopaths?. Science, 337(6096), 846-849.

Asscher, J. J., van Vugt, E. S., Stams, G. J. J., Deković, M., Eichelsheim, V. I., \& Yousfi, S. (2011). The relationship between juvenile psychopathic traits, delinquency and (violent) recidivism: A meta-analysis. Journal of child psychology and psychiatry, 52(11), 11341143.

Barrash, J., Tranel, D., \& Anderson, S. W. (2000). Acquired personality disturbances associated with bilateral damage to the ventromedial prefrontal region. Developmental neuropsychology, 18(3), 355-381.

Barry, C. T., Frick, P. J., DeShazo, T. M., McCoy, M., Ellis, M., \& Loney, B. R. (2000). The 
importance of callous-unemotional traits for extending the concept of psychopathy to children. Journal of abnormal psychology, 109(2), 335.

Barth, A. S. (2007). Double-Edged Sword: The Role of Neuroimaging in Federal Capital Sentencing, A. Am. JL \& Med., 33, 501-522.

Baxter, M. G., \& Murray, E. A. (2002). The amygdala and reward. Nature reviews neuroscience, $3(7), 563-573$.

Bechara, A., Tranel, D., \& Damasio, H. (2000). Characterization of the decision-making deficit of patients with ventromedial prefrontal cortex lesions. Brain,123(11), 2189-2202.

Bermudez-Rattoni, F., \& McGaugh, J. L. (1991). Insular cortex and amygdala lesions differentially affect acquisition on inhibitory avoidance and conditioned taste aversion. Brain research, 549(1), 165-170.

Bertsch, K., Grothe, M., Prehn, K., Vohs, K., Berger, C., Hauenstein, K., ... \& Herpertz, S. C. (2013). Brain volumes differ between diagnostic groups of violent criminal offenders. European archives of psychiatry and clinical neuroscience, 263(7), 593-606.

Birbaumer, N., Veit, R., Lotze, M., Erb, M., Hermann, C., Grodd, W., \& Flor, H. (2005). Deficient fear conditioning in psychopathy: a functional magnetic resonance imaging study. Archives of general psychiatry, 62(7), 799-805.

Bjork, J. M., Chen, G., \& Hommer, D. W. (2012). Psychopathic tendencies and mesolimbic recruitment by cues for instrumental and passively obtained rewards. Biological psychology, 89(2), 408-415.

Blair, R. J. R. (2003). Facial expressions, their communicatory functions and neuro-cognitive substrates. Philosophical Transactions of the Royal Society of London. Series B: 
Biological Sciences, 358(1431), 561-572.

Blair, R. J. R. (2007). The amygdala and ventromedial prefrontal cortex in morality and psychopathy. Trends in cognitive sciences, 11(9), 387-392.

Blair, R. J. R. (2008). Fine cuts of empathy and the amygdala: dissociable deficits in psychopathy and autism. The Quarterly Journal of Experimental Psychology, 61(1), 157170.

Boccaccini, M. T., Murrie, D. C., Clark, J. W., \& Cornell, D. G. (2008). Describing, diagnosing, and naming psychopathy: How do youth psychopathy labels influence jurors?. Behavioral sciences \& the law, 26(4), 487-510.

Boccardi, M., Frisoni, G. B., Hare, R. D., Cavedo, E., Najt, P., Pievani, M., ... \& Tiihonen, J. (2011). Cortex and amygdala morphology in psychopathy. Psychiatry Research: Neuroimaging, 193(2), 85-92.

Boggio, P. S., Campanhã, C., Valasek, C. A., Fecteau, S., Pascual-Leone, A., \& Fregni, F. (2010). Modulation of decision-making in a gambling task in older adults with transcranial direct current stimulation. European Journal of Neuroscience, 31(3), 593597.

Bonta, J., \& Andrews, D. A. (2007). Risk-need-responsivity model for offender assessment and rehabilitation (User Report 2007-06). Ottawa, Ontario: Public Safety Canada.

Book, S.A., Clark, H.J., Forth, A.E., \& Hare, R.D. (2013). The Psychopathy Checklist-Revised and the Psychopathy Checklist: Youth Version. In e.d.s. Archer, R. P., \& Wheeler, E. M., Forensic Uses of Clinical Assessment Instrument, pp.147 - 180, Routledge.

Boyd, R., \& Richerson, P. (1992). Punishment allows the evolution of cooperation (or anything 
else) in sizable groups. Ethology and Sociobiology, 13, 171-195.

Bufkin, J. L., \& Luttrell, V. R. (2005). Neuroimaging studies of aggressive and violent behavior current findings and implications for criminology and criminal justice. Trauma, Violence, \& Abuse, 6(2), 176-191.

Caldwell, M. F., McCormick, D. J., Umstead, D., \& Van Rybroek, G. J. (2007). Evidence of treatment progress and therapeutic outcomes among adolescents with psychopathic features. Criminal justice and behavior, 34(5), 573-587.

Canavero, S. (2014). Criminal Minds: Neuromodulation of the Psychopathic Brain. Frontiers in Human Neuroscience, 5, 124.

Carré, J. M., Hyde, L. W., Neumann, C. S., Viding, E., \& Hariri, A. R. (2013). The neural signatures of distinct psychopathic traits. Social neuroscience, 8(2), 122-135.

Cauffman, E., Kimonis, E. R., Dmitrieva, J., \& Monahan, K. C. (2009). A multimethod assessment of juvenile psychopathy: comparing the predictive utility of the PCL: YV, YPI, and NEO PRI. Psychological assessment, 21(4), 528-542.

Ciaramelli, E., Muccioli, M., Ladavas, E., \& di Pellegrino, G. (2007). Selective deficit in personal moral judgment following damage to ventromedial prefrontal cortex. Social cognitive and affective neuroscience, 2(2), 84-92.

Cleckley, H. M. (1988). The mask of sanity: An attempt to clarify some issues about the so called psychopathic personality, $5^{\text {th }}$ ed, Emily S. Cleckley, Publisher.

Cohn, M. D., Popma, A., van den Brink, W., Pape, L. E., Kindt, M., van Domburgh, L., ... \& Veltman, D. J. (2013). Fear conditioning, persistence of disruptive behavior and psychopathic traits: an fMRI study. Translational psychiatry, 3(10), e319. 
Coid, J. W., Ullrich, S., \& Kallis, C. (2013). Predicting future violence among individuals with psychopathy. The British Journal of Psychiatry, 203(5), 387-388.

Cope, L. M., Ermer, E., Nyalakanti, P. K., Calhoun, V. D., \& Kiehl, K. A. (2014). Paralimbic gray matter reductions in incarcerated adolescent females with psychopathic traits. Journal of abnormal child psychology, 42(4), 659-668.

Cornell, D. G., Warren, J., Hawk, G., Stafford, E., Oram, G., \& Pine, D. (1996). Psychopathy in instrumental and reactive violent offenders. Journal of consulting and clinical psychology, 64(4), 783.

Cornet, L. J., Kogel, C. H., Nijman, H. L., Raine, A., \& Laan, P. H. (2014). Neurobiological changes after intervention in individuals with anti-social behaviour: A literature review. Criminal Behaviour and Mental Health.

Craig, M. C., Catani, M., Deeley, Q., Latham, R., Daly, E., Kanaan, R., ... \& Murphy, D. G. (2009). Altered connections on the road to psychopathy. Molecular psychiatry, 14(10), 946-953.

Dadds, M. R., \& Salmon, K. (2003). Punishment insensitivity and parenting: Temperament and learning as interacting risks for antisocial behavior. Clinical child and family psychology review, 6(2), 69-86.

De Brito, S. A., Mechelli, A., Wilke, M., Laurens, K. R., Jones, A. P., Barker, G. J., ... \& Viding, E. (2009). Size matters: Increased grey matter in boys with conduct problems and callous-unemotional traits. Brain, 132(4), 843-852. 
Decety, J., Michalska, K. J., \& Akitsuki, Y. (2008). Who caused the pain? An fMRI investigation of empathy and intentionality in children. Neuropsychologia,46(11), 26072614.

De Oliveira-Souza, R., Moll, J., Ignácio, F. A., \& Hare, R. D. (2008). Psychopathy in a civil psychiatric outpatient sample. Criminal Justice and Behavior, 35(4), 427-437.

Dolan, M. C., Deakin, J. F. W., Roberts, N., \& Anderson, I. M. (2002). Quantitative frontal and temporal structural MRI studies in personality-disordered offenders and control subjects. Psychiatry Research: Neuroimaging,116(3), 133-149.

Edens, J. F., \& Cahill, M. (2007). Psychopathy in adolescence and criminal recidivism in young adulthood: Longitudinal results from a multi-ethnic sample. Psychological Assessment, $14,57-64$.

Edens, J. F., \& Campbell, J. S. (2007). Identifying youths at risk for institutional misconduct: A meta-analytic investigation of the Psychopathy Checklist measures. Psychological Services, 4, 13-27.

Edens, J. F., Campbell, J. S., \& Weir, J. M. (2007). Youth psychopathy and criminal recidivism: A meta-analysis of the Psychopathy Checklist measures. Law and Human Behavior, 31, $53-75$.

Ermer, E., Cope, L. M., Nyalakanti, P. K., Calhoun, V. D., \& Kiehl, K. A. (2012). Aberrant paralimbic gray matter in criminal psychopathy. Journal of abnormal psychology, 121(3), 649.

Fabian, J. M. (2010). Neuropsychological and neurological correlates in violent and homicidal offenders: A legal and neuroscience perspective. Aggression and Violent Behavior, 15(3), 209-223. 
Fairchild, G., Hagan, C. C., Walsh, N. D., Passamonti, L., Calder, A. J., \& Goodyer, I. M. (2013). Brain structure abnormalities in adolescent girls with conduct disorder. Journal of Child Psychology and Psychiatry, 54(1), 86-95.

Farah, M.J. (2004), Neuroethics: A guide for the perplexed. Cerebrum. 6, 29-38.

Fazel, S., Singh, J. P., Doll, H., \& Grann, M. (2012). Use of risk assessment instruments to predict violence and antisocial behaviour in 73 samples involving 24827 people: systematic review and meta-analysis. BMJ: British Medical Journal, 345.

Fecteau, S., Knoch, D., Fregni, F., Sultani, N., Boggio, P., \& Pascual-Leone, A. (2007a). Diminishing risk-taking behavior by modulating activity in the prefrontal cortex: a direct current stimulation study. The Journal of Neuroscience, 27(46), 12500-12505.

Fecteau, S., Pascual-Leone, A., Zald, D. H., Liguori, P., Théoret, H., Boggio, P. S., \& Fregni, F. (2007b). Activation of prefrontal cortex by transcranial direct current stimulation reduces appetite for risk during ambiguous decision making. The Journal of neuroscience, 27(23), 6212-6218.

Finger, E. C., Marsh, A. A., Blair, K. S., Reid, M. E., Sims, C., Ng, P., ... \& Blair, R. J. R. (2011). Disrupted reinforcement signaling in the orbitofrontal cortex and caudate in youths with conduct disorder or oppositional defiant disorder and a high level of psychopathic traits. American Journal of Psychiatry, 168(2), 152-162.

Finger, E. C., Marsh, A. A., Mitchell, D. G., Reid, M. E., Sims, C., Budhani, S., ... \& Blair, J. R. (2008). Abnormal ventromedial prefrontal cortex function in children with psychopathic traits during reversal learning. Archives of General Psychiatry, 65(5), 586-594. 
Forth, A. E., Kosson, D. S., \& Hare, R. D. (2003). Hare psychopathy checklist: Youth version (PCL: YV). MHS.

Fowler, J. (2005). Altruistic punishment and the origin of cooperation. Proceedings of the National Academy of Sciences, 102 (19), 7027-7049.

Fowles, D. C. (1980). The three arousal model: Implications of Gray's two-factor learning theory for heart rate, electrodermal activity, and psychopathy. Psychophysiology, 17(2), 87-104.

Frick, P. J. (2009). Extending the construct of psychopathy to youth: implications for understanding, diagnosing, and treating antisocial children and adolescents. Canadian Journal of Psychiatry/Revue canadienne de psychiatrie,31(12), 803.

Frick, P. J., Ray, J. V., Thornton, L. C., \& Kahn, R. E. (2014). Can callous-unemotional traits enhance the understanding, diagnosis, and treatment of serious conduct problems in children and adolescents? A comprehensive review. Psychological bulletin, 140(1), 1-57.

Gao, Y., Raine, A., Venables, P. H., Dawson, M. E., \& Mednick, S. A. (2010). Association of poor childhood fear conditioning and adult crime. American Journal of Psychiatry, 167(1), 56-60.

Gatowski, S. I., Dobbin, S. A., Richardson, J. T., Ginsburg, G. P., Merlino, M. L., \& Dahir, V. (2001). Asking the Gatekeepers: A National Survey of Judges on Judging Expert Evidence in a Post-Daubert World. Law and Human Behavior, 25(5), 433-458.

Gazzaniga, M.S. (April 2011). Neuroscience in the Courtroom. Scientific American, 304(4), 5459. 
Giedd, J. N., Blumenthal, J., Jeffries, N. O., Castellanos, F. X., Liu, H., Zijdenbos, A., Tomas, P., Evans, A.C., \& Rapoport, J. L. (1999). Brain development during childhood and adolescence: a longitudinal MRI study. Nature neuroscience, 2(10), 861-863.

Glenn, A. L., \& Raine, A. (2013). Neurocriminology: implications for the punishment, prediction and prevention of criminal behaviour. Nature Reviews Neuroscience, 15, 54-63.

Glenn, A. L., Raine, A., \& Laufer, W. S. (2011). Is it wrong to criminalize and punish psychopaths?. Emotion Review, 3(3), 302-304.

Glenn, A. L., Raine, A., \& Schug, R. A. (2009). The neural correlates of moral decision-making in psychopathy.

Gregory, S., Simmons, A., Kumari, V., Howard, M., Hodgins, S., \& Blackwood, N. (2012). The antisocial brain: psychopathy matters: a structural MRI investigation of antisocial male violent offenders. Archives of general psychiatry,69(9), 962-972.

Gretton, H. M., Hare, R. D., \& Catchpole, R. (2004). Psychopathy and offending from adolescence to adulthood: A 10-year follow-up. Journal of Consulting and Clinical Psychology, 72, 636-645.

Guy, L. S., Edens, J. F., Anthony, C., \& Douglas, K. S. (2005). Does psychopathy predict institutional misconduct among adults? A meta-analytic investigation. Journal of consulting and clinical psychology, 73(6), 1056.

Hans, V. P. (2007). Judges, juries, and scientific evidence. JL \& Pol'y, 16, 19-46.

Hare, R.D. (2003). The Hare Psychopathy Checklist - Revised (PCL-R), $2^{\text {nd }}$ ed, Toronto, Ontario: Multi-Health Systems. 
Harris, G. T., \& Rice, M. E. (2006). Treatment of psychopathy. Handbook of psychopathy, 555572.

Harris, G. T., Rice, M. E., \& Cormier, C. A. (1991). Psychopathy and violent recidivism. Law and human behavior, 15(6), 625 .

Hart, S. D., Kropp, P. R., \& Hare, R. D. (1988). Performance of male psychopaths following conditional release from prison. Journal of consulting and clinical psychology, 56(2), 227.

Hart, S. D., Michie, C., \& Cooke, D. J. (2007). Precision of actuarial risk assessment instruments Evaluating themargins of error'of group v. individual predictions of violence. The British Journal of Psychiatry, 190(49), s60-s65.

Hitchcock, J., \& Davis, M. (1986). Lesions of the amygdala, but not of the cerebellum or red nucleus, block conditioned fear as measured with the potentiated startle paradigm. Behavioral neuroscience, 100(1), 11.

Howner, K., Eskildsen, S. F., Fischer, H., Dierks, T., Wahlund, L. O., Jonsson, T., ... \& Kristiansson, M. (2012). Thinner cortex in the frontal lobes in mentally disordered offenders. Psychiatry Research: Neuroimaging, 203(2), 126-131.

Huebner, T., Vloet, T. D., Marx, I., Konrad, K., Fink, G. R., Herpertz, S. C., \& HerpertzDahlmann, B. (2008). Morphometric brain abnormalities in boys with conduct disorder. Journal of the American Academy of Child \& Adolescent Psychiatry, 47(5), $540-547$.

Jones, A., Laurens, K., Herba, C., Barker, G., \& Viding, E. (2009). Amygdala hypoactivity to fearful faces in boys with conduct problems and callous-unemotional traits. American Journal of Psychiatry, 166(1), 95-102. 
Kahn, R. E., Frick, P. J., Youngstrom, E., Findling, R. L., \& Youngstrom, J. K. (2012). The effects of including a callous-unemotional specifier for the diagnosis of conduct disorder. Journal of child psychology and psychiatry,53(3), 271-282.

Karim, A. A., Schneider, M., Lotze, M., Veit, R., Sauseng, P., Braun, C., \& Birbaumer, N. (2010). The truth about lying: inhibition of the anterior prefrontal cortex improves deceptive behavior. Cerebral Cortex, 20(1), 205-213.

Kaye, D. H., Hans, V. P., Dann, B. M., Farley, E., \& Albertson, S. (2007). Statistics in the jury box: How jurors respond to Mitochondrial DNA match probabilities. Journal of Empirical Legal Studies, 4(4), 797-834.

Kiehl, K. A. (2006). A cognitive neuroscience perspective on psychopathy: evidence for paralimbic system dysfunction. Psychiatry research, 142(2), 107-128.

Kiehl, K. A., \& Hoffman, M. B. (2010). Criminal Psychopath: History, Neuroscience, Treatment, and Economics, The. Jurimetrics, 51, 355.

Kiehl, K. A., Smith, A. M., Hare, R. D., Mendrek, A., Forster, B. B., Brink, J., \& Liddle, P. F. (2001). Limbic abnormalities in affective processing by criminal psychopaths as revealed by functional magnetic resonance imaging. Biological psychiatry, 50(9), 677-684.

Kolla, N.J. \& Brodie, J.D. (2012). Application of Neuroimaging in Relation to Competence to Stand Trial. In ed. Greely, H. \& Simpson, J.R., Neuroimaging in forensic psychiatry: From the clinic to the courtroom, pp. 147-163, John Wiley \& Sons.

Kurzban, R., DeScioli, P., \& O’Brien, E. (2007). Audience effects on moralistic punishment. Evolution and Human Behavior, 28 (2), 75-84. 
LaBar, K. S., Gatenby, J. C., Gore, J. C., LeDoux, J. E., \& Phelps, E. A. (1998). Human amygdala activation during conditioned fear acquisition and extinction: a mixed-trial fMRI study. Neuron, 20(5), 937-945.

Levy, K. (2011). Dangerous Psychopaths: Criminally Responsible but Not Morally Responsible, Subject to Criminal Punishment And to Preventive Detention. San Diego L. Rev., 48, 1299-1396.

Levy, N. (2007). The responsibility of the psychopath revisited. Philosophy, Psychiatry, \& Psychology, 14(2), 129-138.

Liu, J.H. (2011). Early health risk factors for violence: Conceptualization, evidence, and implications. Aggression and Violent Behavior, 16, 63-73.

Loney, B. R., Taylor, J., Butler, M. A., \& Iacono, W. G. (2007). Adolescent psychopathy features: 6-Year temporal stability and the prediction of externalizing symptoms during the transition to adulthood. Aggressive Behavior, 33(3), 242-252.

Lozier, L. M., Cardinale, E. M., VanMeter, J. W., \& Marsh, A. A. (2014). Mediation of the relationship between callous-unemotional traits and proactive aggression by amygdala response to fear among children with conduct problems. JAMA psychiatry.

Lykken, D. T. (1995). The antisocial personalities. Hillsdale, NJ: Erlbaum.

Lynam, D. R., Caspi, A., Moffitt, T. E., Loeber, R., \& Stouthamer-Loeber, M. (2007). Longitudinal evidence that psychopathy scores in early adolescence predict adult psychopathy. Journal of abnormal psychology, 116(1), 155. 
Lynam, D. R., Caspi, A., Moffitt, T. E., Raine, A., Loeber, R., \& Stouthamer-Loeber, M. (2005). Adolescent psychopathy and the Big Five: Results from two samples. Journal of Abnormal Child Psychology, 33(4), 431-443.

Lyon, D. R., \& Ogloff, J. R. P. (2000). Legal and ethical issues in psychopathy assessment. In C. Gacono The clinical and forensic assessment of psychopathy: A practitioner's guide, pp. 139-173, Mahwah, NJ: Lawrence Erlbaum Associates

Maibom, H.L. (2014). To treat a psychopath Theoretical Medicine and Bioethics, 35 (1), 31-42.

Marsh, A. (2013). When viewing empathy-eliciting scenarios, incarcerated men with high psychopathy display differences in brain activity compared with those with low psychopathy. Evidence Based Mental Health, 16(4), 96-96.

Marsh, A. A., Finger, E. C., Fowler, K. A., Adalio, C. J., Jurkowitz, I. T., Schechter, J. C., ... \& Blair, R. J. R. (2013). Empathic responsiveness in amygdala and anterior cingulate cortex in youths with psychopathic traits. Journal of Child Psychology and Psychiatry, 54(8), 900-910.

Marsh, A., Finger, E., Mitchell, D., Reid, M., Sims, C., Kosson, D., ... \& Blair, R. (2008). Reduced amygdala response to fearful expressions in children and adolescents with callous-unemotional traits and disruptive behavior disorders. American Journal of Psychiatry, 165(6), 712-720.

Medina, T.R., \& McCranie, A. (2010). Layering Control: Medicalization, Psychopathy, and Increasing Multi-Institutional Management of Social Problems. In e.d. Pescosolido, B . A., Martin, J. K., McLeod, J. D., \& Rogers, A. Handbook of the sociology of health, illness, and healing: a blueprint for the 21st century, pp.139-158, Springer. 
Mobbs, D., Lau, H. C., Jones, O. D., \& Frith, C. D. (2007). Law, responsibility, and the brain. PLoS biology, 5(4), e103.

Monterosso, J., Royzman, E. B., \& Schwartz, B. (2005). Explaining away responsibility: Effects of scientific explanation on perceived culpability. Ethics \& Behavior, 15(2), 139-158.

Montgomery, P., Burton, J. R., Sewell, R. P., Spreckelsen, T. F., \& Richardson, A. J. (2013). Low blood long chain omega-3 fatty acids in UK children are associated with poor cognitive performance and behavior: A cross-sectional analysis from the DOLAB study. PloS one, 8(6), e66697.

Moriarty, J. C. (2008). Flickering admissibility: neuroimaging evidence in the US courts. Behavioral sciences \& the law, 26(1), 29-49.

Morse, S. J. (2008). Psychopathy and criminal responsibility. Neuroethics, 1(3), 205-212. Morse, S.J., \& Newsome, W.T. (2013). Criminal Responsibility, Criminal Competence and Criminal Law Prediction. In e.d. Morse, Stephen J. and Adina Roskies, A Primer on Criminal Law and Neuroscience, pp.150-178, Oxford University Press.

Motzkin, J. C., Newman, J. P., Kiehl, K. A., \& Koenigs, M. (2011). Reduced prefrontal connectivity in psychopathy. The Journal of Neuroscience, 31(48), 17348-17357.

Müller, J. L., Sommer, M., Wagner, V., Lange, K., Taschler, H., Röder, C. H., ... \& Hajak, G. (2003). Abnormalities in emotion processing within cortical and subcortical regions in criminal psychopaths: evidence from a functional magnetic resonance imaging study using pictures with emotional content.Biological psychiatry, 54(2), 152-162. 
Nadelhoffer, T., Bibas, S., Grafton, S., Kiehl, K. A., Mansfield, A., Sinnott-Armstrong, W., \& Gazzaniga, M. (2012). Neuroprediction, violence, and the law: Setting the stage. Neuroethics, 5(1), 67-99.

Newman, J. P., \& Kosson, D. S. (1986). Passive avoidance learning in psychopathic and nonpsychopathic offenders. Journal of abnormal psychology,95(3), 252.

Pardini, D. A., Raine, A., Erickson, K., \& Loeber, R. (2014). Lower amygdala volume in men is associated with childhood aggression, early psychopathic traits, and future violence. Biological psychiatry, 75(1), 73-80.

Porter, S., Birt, A. R., \& Boer, D. P. (2001). Investigation of the criminal and conditional release profiles of Canadian federal offenders as a function of psychopathy and age. Law and human behavior, 25(6), 647.

Porter, S., Brinke, L., \& Wilson, K. (2009). Crime profiles and conditional release performance of psychopathic and non-psychopathic sexual offenders.Legal and Criminological Psychology, 14(1), 109-118.

Prehn, K., Schlagenhauf, F., Schulze, L., Berger, C., Vohs, K., Fleischer, M., ... \& Herpertz, S. C. (2013). Neural correlates of risk taking in violent criminal offenders characterized by emotional hypo-and hyper-reactivity. Social neuroscience, 8(2), 136-147.

Pridmore, S., Chambers, A., \& McArthur, M. (2005). Neuroimaging in psychopathy. Australian and New Zealand Journal of Psychiatry, 39(10), 856-865.

Puig, M. V., \& Gulledge, A. T. (2011). Serotonin and prefrontal cortex function: neurons, networks, and circuits. Molecular neurobiology, 44(3), 449-464.

Raine A. The psychopathology of crime: Criminal behavior as a clinical disorder. Academic Press; San Diego: 1993. 
Raine, A. (2008). From genes to brain to antisocial behavior. Current Directions in Psychological Science, 17, 323-328.

Raine, A., Meloy, J. R., Bihrle, S., Stoddard, J., LaCasse, L., \& Buchsbaum, M. S. (1998). Reduced prefrontal and increased subcortical brain functioning assessed using positron emission tomography in predatory and affective murderers. Behavioral sciences \& the law, 16(3), 319-332.

Raine, A., Portnoy, J., Liu, J., Mahoomed, T., \& Hibbeln, J. R. (2014). Reduction in behavior problems with omega-3 supplementation in children aged 8-16 years: a randomized, double-blind, placebo-controlled, stratified, parallel-group trial. Journal of Child Psychology and Psychiatry. DOI: 10.1111/jcpp.12314.

Richards, H. J., Casey, J. O., \& Lucente, S. W. (2003). Psychopathy and treatment response in incarcerated female substance abusers. Criminal Justice and Behavior, 30(2), 251-276.

Rilling, J. K., Glenn, A. L., Jairam, M. R., Pagnoni, G., Goldsmith, D. R., Elfenbein, H. A., \& Lilienfeld, S. O. (2007). Neural correlates of social cooperation and non-cooperation as a function of psychopathy. Biological psychiatry, 61(11), 1260-1271.

Roper v. Simmons, 543 U.S. 551, 125 S. Ct. 1183, 161 L. Ed. 2d 1 (2005).

Ruff, C. C., Ugazio, G. \& Fehr E. (2013). Changing social norm compliance with noninvasive brain stimulation. Science, 342(6157), 482-484.

Ryan, A. S., Astwood, J. D., Gautier, S., Kuratko, C. N., Nelson, E. B., \& Salem Jr, N. (2010). Effects of long-chain polyunsaturated fatty acid supplementation on neurodevelopment in childhood: a review of human studies. Prostaglandins, Leukotrienes and Essential Fatty Acids (PLEFA), 82(4), 305-314. 
Salekin, R. T. (2002). Psychopathy and therapeutic pessimism: Clinical lore or clinical reality?. Clinical psychology review, 22(1), 79-112.

Seagrave, D., \& Grisso, T. (2002). Adolescent Development and the Measurement of Juvenile Psychopathy. Law and Human Behavior, 26(2), 219-239.

Seara-Cardoso, A., \& Viding, E. (2014). Functional Neuroscience of Psychopathic Personality in Adults. Journal of Personality. DOI: 10.1111/jopy.12113.

Schiltz, K., Witzel, J., Northoff, G., Zierhut, K., Gubka, U., Fellmann, H., ... \& Bogerts, B. (2007). Brain pathology in pedophilic offenders: evidence of volume reduction in the right amygdala and related diencephalic structures. Archives of General Psychiatry, 64(6), 737-746.

Schuchardt, J. P., Huss, M., Stauss-Grabo, M., \& Hahn, A. (2010). Significance of long-chain polyunsaturated fatty acids (PUFAs) for the development and behaviour of children. European journal of pediatrics, 169(2), 149-164.

Scott, S. K., Young, A. W., Calder, A. J., Hellawell, D. J., Aggleton, J. P., \& Johnsons, M. (1997). Impaired auditory recognition of fear and anger following bilateral amygdala lesions. Nature, 385(6613), 254-257.

Sebastian, C. L., McCrory, E. J., Cecil, C. A., Lockwood, P. L., De Brito, S. A., Fontaine, N. M., \& Viding, E. (2012). Neural responses to affective and cognitive theory of mind in children with conduct problems and varying levels of callous-unemotional traits. Archives of general psychiatry, 69(8), 814-822.

Serin, R. C., Peters, R. D., \& Barbaree, H. E. (1990). Predictors of psychopathy and release outcome in a criminal population. Psychological Assessment: A Journal of Consulting and Clinical Psychology, 2(4), 419. 
Sevecke, K., Lehmkuhl, G., \& Krischer, M. K. (2009). Examining relations between psychopathology and psychopathy dimensions among adolescent female and male offenders. European child \& adolescent psychiatry, 18(2), 85-95.

Schwalbe, C. S. (2007). Risk assessment for juvenile justice: a meta-analysis. Law and human behavior, 31(5), 449-462.

Sharp, C., \& Kine, S. (2008). The assessment of juvenile psychopathy: Strengths and weaknesses of currently used questionnaire measures. Child and Adolescent Mental Health, 13(2), $85-95$.

Shirtcliff, E. A., Vitacco, M. J., Graf, A. R., Gostisha, A. J., Merz, J. L., \& Zahn-Waxler, C. (2009). Neurobiology of empathy and callousness: implications for the development of antisocial behavior. Behavioral sciences \& the law, 27(2), 137-171.

Skeem, J. L., Monahan, J., \& Mulvey, E. P. (2002). Psychopathy, treatment involvement, and subsequent violence among civil psychiatric patients. Law and human behavior, 26(6), 577.

Skeem, J. L., Polaschek, D. L., Patrick, C. J., \& Lilienfeld, S. O. (2011). Psychopathic personality bridging the gap between scientific evidence and public policy. Psychological Science in the Public Interest, 12(3), 95-162.

Snead, O. C. (2007). Neuroimaging and the'Complexity'of Capital Punishment. New York University Law Review, 82(5), 1265-1339.

Sowell, E. R., Peterson, B. S., Thompson, P. M., Welcome, S. E., Henkenius, A. L., \& Toga, A. W. (2003). Mapping cortical change across the human life span. Nature neuroscience, $6(3), 309-315$. 
Stockdale, K. C., Olver, M. E., \& Wong, S. C. P. (2010). The Psychopathy Checklist: Youth Version and adolescent and adult recidivism: Considerations with respect to gender, ethnicity, and age. Psychological Assessment, 22, 768-781.

Tiihonen, J., Hodgins, S., Vaurio, O., Laakso, M., Repo, E., Soininen, H., ... \& Savolainen, L. (2000, November). Amygdaloid volume loss in psychopathy. InSociety for Neuroscience Abstracts (Vol. 2017, pp. 628-446). The Guilford Press.

Viding, E., Fontaine, N. M., \& McCrory, E. J. (2012). Antisocial behaviour in children with and without callous-unemotional traits. Journal of the Royal Society of Medicine, 105(5), 195-200.

Viding, E., Sebastian, C. L., Dadds, M. R., Lockwood, P. L., Cecil, C. A., De Brito, S. A., \& McCrory, E. J. (2012). Amygdala response to preattentive masked fear in children with conduct problems: the role of callous-unemotional traits. American journal of psychiatry, 169(10), 1109-1116.

Wallace, G. L., White, S. F., Robustelli, B., Sinclair, S., Hwang, S., Martin, A., \& Blair, R. J. R. (2014). Cortical and subcortical abnormalities in youths with conduct disorder and elevated callous-unemotional traits. Journal of the American Academy of Child \& Adolescent Psychiatry, 53(4), 456-465.

White, S. F., Marsh, A. A., Fowler, K. A., Schechter, J. C., Adalio, C., Pope, K., ... \& Blair, R. J. R. (2012). Reduced amygdala response in youths with disruptive behavior disorders and psychopathic traits: decreased emotional response versus increased top-down attention to nonemotional features.American Journal of Psychiatry, 169(7), 750-758.

White, S. F., Pope, K., Sinclair, S., Fowler, K. A., Brislin, S. J., Williams, W. C., ... \& Blair, R. J. R. (2013). Disrupted expected value and prediction error signaling in youths with 
disruptive behavior disorders during a passive avoidance task. American Journal of Psychiatry, 170(3), 315-323.

Yang, Y., Glenn, A. L., \& Raine, A. (2008). Brain abnormalities in antisocial individuals: implications for the law. Behavioral sciences \& the law, 26(1), 65-83.

Yang, Y., \& Raine, A. (2009). Prefrontal structural and functional brain imaging findings in antisocial, violent, and psychopathic individuals: a meta-analysis.Psychiatry Research: Neuroimaging, 174(2), 81-88.

Yang, Y., Raine, A., Colletti, P., Toga, A. W., \& Narr, K. L. (2010). Morphological alterations in the prefrontal cortex and the amygdala in unsuccessful psychopaths. Journal of abnormal psychology, 119(3), 546.

Yang, Y., Raine, A., Lencz, T., Bihrle, S., LaCasse, L., \& Colletti, P. (2005). Volume reduction in prefrontal gray matter in unsuccessful criminal psychopaths. Biological psychiatry, 57(10), 1103-1108.

Yang, Y., Raine, A., Narr, K. L., Colletti, P., \& Toga, A. W. (2009). Localization of deformations within the amygdala in individuals with psychopathy. Archives of General Psychiatry, 66(9), 986-994.

Yang, M., Wong, S. C., \& Coid, J. (2010). The efficacy of violence prediction: a meta-analytic comparison of nine risk assessment tools. Psychological bulletin, 136(5), 740-767.

Young, L., Bechara, A., Tranel, D., Damasio, H., Hauser, M., \& Damasio, A. (2010). Damage to ventromedial prefrontal cortex impairs judgment of harmful intent. Neuron, 65(6), 845851. 